\title{
Global warming, climate change, air pollution and allergies
}

\author{
Gennaro D'Amato' and Cezmi Akdis² \\ ${ }^{1}$ Division of Pneumology and Allergology High Speciality "A.Cardarelli" \\ ${ }^{2}$ University of Zurich
}

July 20, 2020

EDITORIAL The average global temperatures on our planet are increasing due to rising anthropogenic greenhouse gases in the atmosphere, in particular carbon dioxide $\left(\mathrm{CO}_{2}\right) \cdot{ }^{1,2}$ There is an urgent need to call for action on global warming, which is resulting in extreme weather and related catastrophes. ${ }^{1,2}$ The Earth's rising temperature is evidenced by warming of the oceans, melting glaciers, rising sea levels, and the diminished snow cover in the Northern Hemisphere. Climate-related factors can affect interactive atmospheric components (chemical and biological) and their interrelationship with human health.

Climate change, a physics and meteorological event that affects health in the whole biosphere started to receive attention around the mid-twentieth century. Air pollution is the driving force of the Earth's warming powered by the greenhouse effect (Figure 1). Environmental changes are occurring in frequency, intensity, type of precipitation, and extreme weather events, such as heatwaves, droughts, floods, blizzards, thunderstorms, sandstorms, and hurricanes. These are real and daunting challenges for the human and biosphere health, impacting the food and water supplies. ${ }^{1,2}$ Urbanization, with its high level of vehicle emissions and westernized lifestyle, is linked to the rising levels of particulate matter in the air, food supplies, soil, freshwater, and oceans. These environmental changes are correlated with the increased frequency of respiratory allergic diseases and bronchial asthma observed over recent decades in most industrialized countries and is continuously rising in developing countries. ${ }^{1-5}$

This issue of Allergy focuses on the interrelationship between climate change, air pollution and human health. ${ }^{3-7}$ Climate change is an important medical aspect in allergology as we are observing an increasing incidence of allergic diseases indirectly related to rising temperatures and are becoming a high socio-economic burden. ${ }^{1-3,8}$ Allergies and asthma appear to be at the front line of the sequelae of climate change along with infectious and cardiovascular diseases. ${ }^{1,5}$

Cecchi et al. focus on the development and exacerbation of allergic diseases can be explained in terms of the exposome, a concept that includes all the environmental exposures from conception onwards. Multiple factors can trigger a pollen-induced respiratory allergy, such as airborne endotoxin levels and microbial composition of pollen, and these comprise a "pollen exposome". 4,9

Susan Prescott has written an editorial in this issue bringing the attention to climate change and bidiversity aspects. At the time of Neil Armstrong's lunar landing 50 years ago, Prof. Rene Dubos, a renowned microbiologist, delivered the seminal lecture "The Spaceship Earth". He was ahead of his time and warned of an "altered immunity" driven by environmental problems and loss of biodiversity. Most of his predictions proved correct and we are now understanding at a molecular level the pathophysiological mechanisms involved in allergic diseases. ${ }^{8}$

Climate change indirectly affects allergies by altering the pollen concentrations, allergenic potential, composition, migration of species and growth of new ones. Air pollution and climate change have resulted in the faster growth of allergenic plants, increasing the aeroallergen load for patients with inhalant allergy. Phenological studies indicate longer pollen seasons and emerge earlier in the year. ${ }^{1,4,5,8}$ Pollen and mold allergies 
are generally used to evaluate the interrelationship between air pollution and allergic respiratory diseases, such as rhinitis and asthma. Studies show that plants exhibit enhanced photosynthesis and reproductive effects and produce more pollen as a response to high atmospheric levels of $\mathrm{CO}_{2} \cdot{ }^{1,4,8}$ Pollen allergens have been demonstrated to trigger the release of pro-inflammatory and immunomodulatory mediators that accelerate the onset of allergy and the IgE-mediated sensitization. Lightning storms or wet conditions rupture the pollen grains releasing the allergenic proteins that cause asthma exacerbations in patients with pollinosis (thunderstorm-asthma). ${ }^{1,3,4,7,10}$ As a result of climate change, patients with seasonal allergic rhinoconjunctivitis and asthma have more intense symptoms and need stronger medication. ${ }^{1,4,8}$ In addition to respiratory illnesses, Fairweather et al. demonstrate the effect of environmental changes on cardiovascular, brain and mind, gastrointestinal, skin, immunologic and metabolic effects. ${ }^{1,3,4,7}$ The migration of stinging and biting insects to cooler climates has caused an increase in insect allergies in those areas.

Prunicki et al. focus on the contribution of wildfires and deforestation and their contribution to global warming and immunological effects. It should be noted that in the last fifty years, half of the pluvial forests on Earth have been lost. Deforestation and forestation degradation is estimated to occur at a rate of 13 million hectares per year, mostly for agricultural purposes. Wildfires are becoming increasingly frequent, posing a serious risk to human health. The fine particulate matter $\left(\mathrm{PM}_{2.5}\right)$ in wildfire smoke exacerbates asthma attacks, among other health problems. A study of 67 subjects demonstrated that those exposed to wildfire smoke had significantly higher levels of C-reactive protein and IL-1 $\beta$ compared with controls. ${ }^{6}$ The elevated levels of these two biomarkers are indicative of airway inflammation.

Global warming and climate change need actions throughout the whole world with joined forces of all capabilities. These efforts are sometimes hampered by the unresponsiveness of governmental institutions and the general population, the lack of infrastructure and poverty. An action plan is needed to disseminate information on health-related problems associated with climate change. Patients with pollen allergies or asthma should be educated on the higher health risk during a thunderstorm or pollen season and the need for appropriate medication if staying outdoors. In collaboration with environmental organizations, physicians should take the lead to promote actions to mitigate air pollution and advocate the need to reduce global warming to protect our health. 


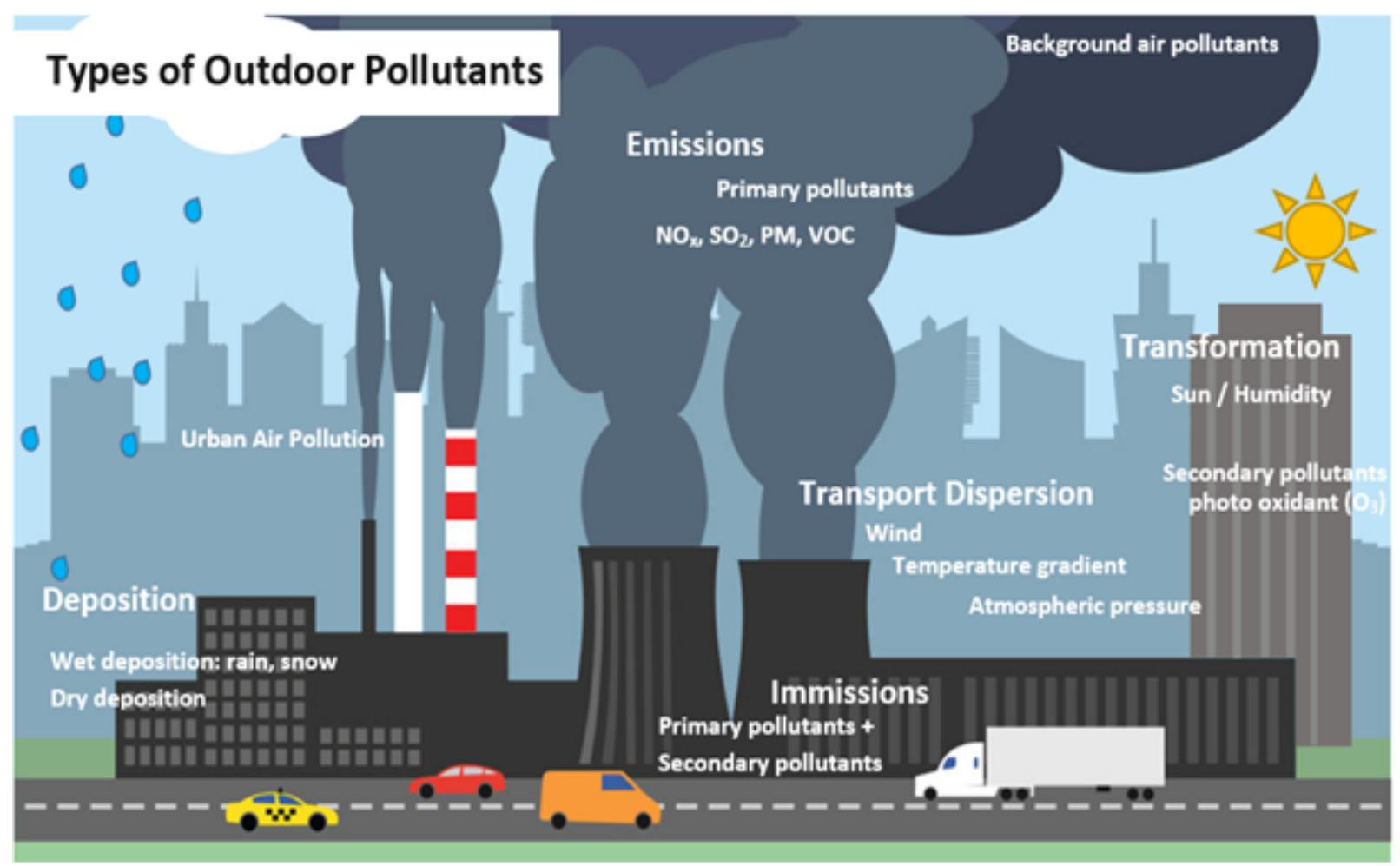

Figure 1. Types of outdoor pollutants and different ways of exposure. ${ }^{11}$

\section{Text Box:}

Intergovernmental Panel on Climate Change (IPCC) 2018 Global warming of $1.5{ }^{\circ} \mathrm{C}$ : Summary for policymakers. Geneva IPCC. ${ }^{12}$ IPCC 2018 Special Report-Global Warming of $1.5{ }^{\circ} \mathrm{C}$ asserts that emissions of carbon dioxide $\left(\mathrm{CO}_{2}\right)$ caused by human activity must reach "net zero" by 2050 to keep the average rise in global temperature at $1.5{ }^{\circ} \mathrm{C}$ above preindustrial levels to reduce catastrophic climate change risk on populations. The Report highlights that "temperature extremes on land are projected to warm more than the global mean surface temperature (high confidence); extreme hot days in mid-latitudes warm by up to about $5{ }^{\circ} \mathrm{C}$ at global warming of $1.5{ }^{\circ} \mathrm{C}$ and about $4{ }^{\circ} \mathrm{C}$ at $2{ }^{\circ} \mathrm{C}$, and extreme cold nights in high latitudes warm by up to about $4.5^{\circ} \mathrm{C}$ at $1.5{ }^{\circ} \mathrm{C}$ and about $6{ }^{\circ} \mathrm{C}$ at $2{ }^{\circ} \mathrm{C}$ (high confidence). The number of hot days is projected to increase in most land regions, with the highest increases in the tropics (high confidence)".

\section{References}

1. D'Amato G, Holgate ST, Pawankar R, et al. Meteorological conditions, climate change, new emerging factors, and asthma and related allergic disorders. A statement of the World Allergy Organization. The World Allergy Organization journal. 2015;8(1):25.

2. Haines A, Ebi K. The Imperative for Climate Action to Protect Health. The New England journal of medicine. 2019;380(3):263-273.

3. Fairweather V, E. H, C. T-H. Climate change and health.Allergy. 2020;Manuscript accepted.

4. Cecchi L, D'Amato G, Annesi-Maesano I. Climate change and outdoor aeroallergens related to allergy and asthma: Taking the exposome into account. Allergy. 2020.

5. D'Amato G, Chong-Neto HJ, Monge Ortega OP, et al. The effects of climate change on respiratory allergy and asthma induced by pollen and mold allergens. Allergy. 2020. 
6. Prunicki MM, Dant CC, Cao S, et al. Immunologic effects of forest fire exposure show increases in IL-1 $\beta$ and CRP. Allergy. 2020.

7. D'Amato G, Annesi-Maesano I, Cecchi L, D'Amato M. Latest news on relationship between thunderstorms and respiratory allergy, severe asthma, and deaths for asthma. 2019;74(1):9-11.

8. Prescott SL. Allergy as a sentinel measure of planetary health and biodiversity loss.n/a(n/a).

9. Agache I, Miller R, Gern JE, et al. Emerging concepts and challenges in implementing the exposome paradigm in allergic diseases and asthma: a Practall document. Allergy. 2019;74(3):449-463.

10. Hew M, Lee J, Susanto NH, et al. The 2016 Melbourne thunderstorm asthma epidemic: Risk factors for severe attacks requiring hospital admission. Allergy. 2019;74(1):122-130.

11. Pénard-Morand C, Annesi-Maesano I. Air pollution: from sources of emissions to health effects. Breathe. 2004;1(2):108-119.

12. Governments must take heed of latest IPCC assessment. Nature.2018;562(7726):163. 